\title{
Systemic modulation of stress and immune parameters in patients treated for prostate adenocarcinoma by intensity-modulated radiation therapy or stereotactic ablative body radiotherapy
}

\author{
B. Frey ${ }^{1} \cdot$ J. Mika $^{2} \cdot$ K. Jelonek ${ }^{3}$ L. Cruz-Garcia ${ }^{4}$ C. Roelants ${ }^{5} \cdot$ I. Testard ${ }^{6} \cdot$ N. Cherradi7 $\cdot$ K. Lumniczky $^{8}$.

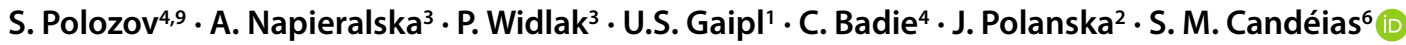

Received: 12 February 2020 / Accepted: 12 May 2020 / Published online: 9 June 2020

(c) The Author(s) 2020

\begin{abstract}
Background In this exploratory study, the impact of local irradiation on systemic changes in stress and immune parameters was investigated in eight patients treated with intensity-modulated radiation therapy (IMRT) or stereotactic ablative body radiotherapy (SABR) for prostate adenocarcinoma to gain deeper insights into how radiotherapy (RT) modulates the immune system.

Patients and methods RT-qPCR, flow cytometry, metabolomics, and antibody arrays were used to monitor a panel of stress- and immune-related parameters before RT, after the first fraction (SABR) or the first week of treatment (IMRT), after the last fraction, and 3 weeks later in the blood of IMRT $(N=4)$ or $\operatorname{SABR}(N=4)$ patients. Effect size analysis was used for comparison of results at different timepoints.

Results Several parameters were found to be differentially modulated in IMRT and SABR patients: the expression of $T G F B 1, I L 1 B$, and CCL3 genes; the expression of HLA-DR on circulating monocytes; the abundance and ratio of phosphatidylcholine and lysophosphatidylcholine metabolites in plasma. More immune modulators in plasma were modulated during IMRT than SABR, with only two common proteins, namely GDF-15 and Tim-3.

Conclusion Locally delivered RT induces systemic modulation of the immune system in prostate adenocarcinoma patients. IMRT and SABR appear to specifically affect distinct immune components.
\end{abstract}

Keywords Ionizing radiation · Biomarkers of radiation exposure $\cdot$ Prostate cancer - Systemic immune modulation · Immunophenotyping

B. Frey and J. Mika contributed equally to this work.

Electronic supplementary material The online version of this article (https://doi.org/10.1007/s00066-020-01637-5) contains supplementary material, which is available to authorized users.

\section{S. M. Candéias}

serge.candeias@cea.fr

1 Department of Radiation Oncology, Universitätsklinikum Erlangen, Friedrich-Alexander-Universität Erlangen-Nürnberg, 91054 Erlangen, Bavaria, Germany

2 Department of Data Science and Engineering, Silesian University of Technology, 44-100 Gliwice, Poland

3 Maria Sklodowska-Curie National Research Institute of Oncology, Gliwice Branch, 44-102 Gliwice, Poland
4 Centre for Radiation, Chemical and Environmental Hazards, Cancers Mechanisms and Biomarkers group, Public Health England, Chilton, Didcot, OX11 ORQ, Oxfordshire, UK

5 Inovarion, 75005 Paris, France

6 Univ. Grenoble Alpes, CEA, CNRS, IRIG-LCBM-UMR5249, 38054 Grenoble, France

7 Univ. Grenoble Alpes, INSERM, CEA, IRIG-BCI-UMR_S1036, 38054 Grenoble, France

8 National Public Health Center, 1097 Budapest, Hungary

9 HQ Science Limited, 5 The Quay, PE27 5AR St. Ives, Cambridgeshire, United Kingdom 


$\begin{array}{ll}\text { Abbreviations } \\ \text { ADT } & \text { Androgen deprivation therapy } \\ \text { BAFF } & \text { B-cell activation factor } \\ \text { CCNG1 } & \text { Cyclin G1 } \\ \text { CD31 } & \begin{array}{l}\text { Platelet and endothelial cell adhesion } \\ \text { molecule 1 }\end{array} \\ \text { CRP } & \text { C-reactive protein } \\ \text { DDB2 } & \text { Damage-specific DNA binding protein 2 } \\ \text { DDPIV } & \text { Dipeptidyl peptidase 4 } \\ \text { FDXR } & \text { Ferredoxin reductase } \\ \text { GADD45 } & \text { Growth arrest and DNA damage inducible } \\ \text { GDF-15 } & \text { Growth and differentiation factor 15 } \\ \text { IGFBP } & \text { Insulin-like growth factor binding protein } \\ \text { IL } & \text { Interleukin } \\ \text { IMRT } & \text { Intensity-modulated radiation therapy } \\ \text { LPC } & \text { Lysophosphatidylcholine } \\ \text { MDM2 } & \text { Mouse double minute 2 homolog } \\ \text { MMP 9 } & \text { Matrix metallopeptidase } 9 \\ \text { PBLs } & \text { Peripheral blood lymphocytes } \\ \text { PC } & \text { Phosphatidyl choline } \\ \text { PD-1 } & \text { Programmed death receptor 1 } \\ \text { PD-L1 } & \text { Programmed death receptor ligand 1 } \\ \text { RANTES } & \text { Regulated on activation, normal T cell ex- } \\ & \text { pressed and secreted } \\ \text { RT } & \text { Radiotherapy } \\ \text { SABR } & \text { Stereotactic ablative body radiotherapy } \\ \text { SESN1 } & \text { Sestrin 1 } \\ \text { SHBG } & \text { Sex hormone-binding globulin } \\ \text { Tim-3 } & \text { T-cell immunoglobulin and mucin domain- } \\ & \text { containing 3 } \\ \text { TLR } & \text { Toll-like receptor } \\ \text { VCAM-1 } & \text { Vascular cell adhesion molecule 1 } \\ & \end{array}$

\section{Background}

Approximately $50 \%$ of all cancer patients will receive radiotherapy (RT) during their course of illness. RT aims to kill tumor cells while sparing as much as possible of the surrounding healthy tissues [1]. Intensity-modulated radiation therapy (IMRT) and stereotactic ablative body radiotherapy (SABR) are used to perform a more precise irradiation of the tumor volume [2]. While radiation delivery during IMRT is conventionally fractionated (e.g., 2Gy/ fraction, 5 days/week), it is hypofractionated during SABR (e.g., 7.25 Gy/fraction, 5 fractions every second day). Thus, widely different RT protocols are nowadays used for the treatment of similar tumor entities. RT has long been regarded as local therapy, but this point of view changed when data on systemic effects of locally delivered radiation were collected [3]. Biomarkers of radiation exposure have been discovered [4] in the blood of patients after local [5, 6] or total body [7-9] irradiation. These bioindicators include genes such as $F D R X$ (coding for ferredoxin reductase, a mitochondrial protein involved in electron transport), $D D B 2$ (coding for the damage-specific DNA binding protein 2, involved in DNA repair), MDM2 (coding for the mouse double minute 2 proto-oncogene, involved in the regulation of p53 degradation), and SESN1, GADD45, and CCNG1 (coding, respectively, for the sestrin 1 protein, the growth arrest and DNA damage-inducible protein 45 , and the cyclin G1 protein, involved in the inhibition of cell cycle and growth arrest in stressful conditions). Expression of these genes is induced by p53 after activation of the radiationinduced DNA damage response checkpoints. Interestingly, the expression of some inflammatory genes such as $A R G I$ (coding for arginase 1, involved in amino acid metabolism and cell proliferation), BCL2L1 (coding for a protein of the BCL2 family, involved in the control of apoptosis), and MYC (coding for the MYC proto-oncogene, involved in cell cycle progression, apoptosis, and cellular transformation) is also found to be dysregulated [8]. While expression of $A R G 1$ and $B C L 2 L 1$ was upregulated, MYC expression was decreased in the blood of cancer patients during RT. These findings show that RT can result in long-term modification of gene expression and potential immunomodulatory effects [3]. In fact, tumor development is intimately linked to the negative modulation of immune cell functions [10]. Tumor cells can, for example, up-regulate their expression of immune checkpoint molecules such as programmed death ligand 1 (PD-L1), making them, e.g., less susceptible to killing by cytotoxic $\mathrm{T}$ lymphocytes. It has been proposed that the anti-tumor efficiency of RT can benefit from a synergy of concomitant re-activation of the immune system [11-13].

Systemic effects of ionizing radiation could also be observed at the level of the proteome, including cytokines, and metabolome in the blood of cancer patients treated with RT [14]. Early changes in the plasma level of a collection of cytokines were, for example, associated with toxicity in patients treated for lung cancer, and this response was modified by the combination of chemotherapy with RT [15]. The intensity of radiation-induced toxicity, including the inflammatory response, is one key factor affecting RT-related changes in the blood proteome [16]. RT-related changes could be also detected in the serum lipidome and dynamic radiation-induced changes in the levels of phosphatidylcholines (PCs) and lysophosphatidylcholines (LPCs) were observed in patients treated for head and neck cancer [17]. LPCs are pro-inflammatory lipids involved in atherosclerosis [18] and an increased plasma LPC/PC ratio has been reported in certain pro-inflammatory conditions [19]. It was recently reported that the LPC/PC ratio increased in the serum of whole-body-irradiated mice [20]. Hence, this parameter represents a potential inflammationrelated metabolomic marker of the response to radiation. 
However, only few data exist on joint analyses of the manifold stress and immune changes that might occur following local treatment of solid tumors such as prostate adenocarcinoma. Such information could shed further light on how a distinct RT scheme impacts at the systemic level and might help to improve multimodal therapies in the future.

In this exploratory study, we therefore complementarily analyzed the expression of stress-response and inflammatory cytokine genes, the modulation of immune cell populations, changes in metabolites, and changes in cytokines levels in the blood of a group of 8 patients undergoing RT for prostate adenocarcinoma. As a first attempt to find out whether modulation of these parameters at the systemic level depends on factors such as the irradiated volume, the dose delivered per fraction, the dose rate, and the total dose received, biomaterial of patients who were treated with two markedly different RT modalities, namely IMRT and SABR, was used for the analyses.

\section{Materials and methods}

\section{Patients and RT treatment}

Male patients diagnosed with prostate adenocarcinoma aged from 63 to 83 years (median 70 years) were recruited for the exploratory study. These patients had no surgery and had not received chemotherapy previously. However, some of them were subjected to androgen-deprivation therapy (ADT), as indicated in Supplementary Table 1. Four patients were treated with photon IMRT (volumetric arc therapy, VMAT; energy $6 \mathrm{MV}$, dose rate $3 \mathrm{~Gy} / \mathrm{min}$ ) with a daily fraction of $2 \mathrm{~Gy}$, according to the conventional five times a week irradiation scheme. The total radiation dose delivered to prostate and half of seminal vesicles (clinical target volume, CTV) was $78 \mathrm{~Gy}$; during the first 22 days of RT, the CTV additionally included the region of the pelvic lymph nodes (total dose of $44 \mathrm{~Gy}$ ). Overall treatment time was in the range of 53-57 days. Another four patients were treated with SABR using a CyberKnife (Accuray Inc., Chesapeake Terrace Sunnyvale, CA, USA) treatment unit according to the scheme 5 fractions of 7.25 Gy every second day (energy $6 \mathrm{MV}$, dose rate $9 \mathrm{~Gy} / \mathrm{min}$ ). The total radiation dose delivered to the CTV was $36.25 \mathrm{~Gy}$ and overall treatment time was in the range of 9-12 days. The CTV in these patients included the prostate and base of the seminal vesicles. All recruited patients signed informed consent indicating their conscious and voluntary participation. One IMRT patient died from a non-cancer-related cause 3 months after RT completion; the seven other patients are still alive 3 years after treatment (Supplementary Table 1).

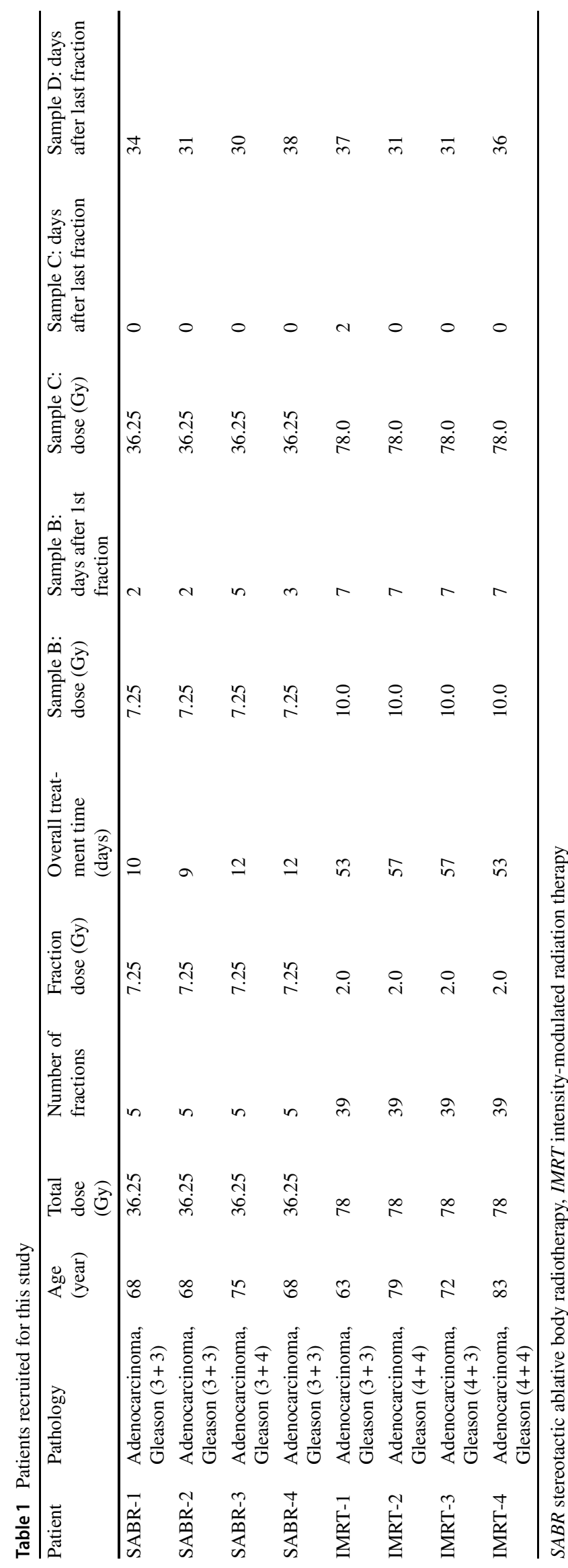




\section{a SABR: 5 x 7.25 Gy}

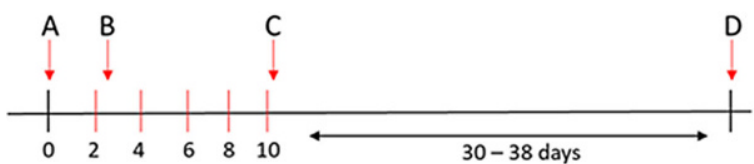

b IMRT: 39 x 2 Gy

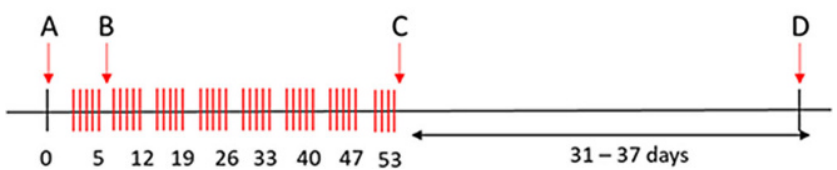

Fig. 1 Schematic presentation of the blood collection timeline of the prostate adenocarcinoma patients treated with SABR (a) and IMRT (b). Red lines represent radiation fractions of $7.25 \mathrm{~Gy}$ and $2 \mathrm{~Gy}$ for SABR and IMRT, respectively. The approximative days of delivery are indicated under the time axis: for each fraction for SABR and at the end of each group of 5 fractions for IMRT. Please note the different time scale for the different RT modalities. SABR stereotactic ablative body radiotherapy, IMRT intensity-modulated radiation therapy

Whole blood of the patients was collected within a week before the start of treatment (sample A), approximately $40 \mathrm{~h}$ after the fifth IMRT fraction (cumulative dose $10 \mathrm{~Gy}$ ) or after the first SABR fraction (sample B), within $6 \mathrm{~h}$ after the last fraction (sample C), and approximately 5 weeks after the last fraction (sample D). A schematic timeline of blood collection is presented in Fig. 1. The blood collection times and doses are specified for each patient in Table 1, while a full description of the patients, their pathology, and the treatment is provided in Supplementary Table 1. This study was carried out in accordance with the Bioethical Committee in the Maria Sklodowska-Curie Institute, Warszawa, approval number 27/2015 from 18/08/2015.

\section{RNA isolation and reverse transcription}

Total RNA from samples collected in PAXgene tubes from RT patients was extracted with the PAXgene Blood miRNA kit (Qiagen, PreAnalytiX GmbH, Hilden, Germany) using a robotic workstation Qiacube (Qiagen, Manchester, UK). The quantity of isolated RNA was determined by spectrophotometry with a ND-1000 NanoDrop and quality was assessed using a Tapestation 220 (Agilent Technologies, Santa Clara, CA, USA). cDNA was prepared from $350 \mathrm{ng}$ of total RNA using the High Capacity cDNA reverse transcription kit (Applied Biosystems, FosterCity, CA, USA) according to the manufacturer's protocol. Alternatively, total RNA was reverse-transcribed using the HS-RT100 kit (SigmaAldrich, L'Isle d'Abeau, France) with anchored oligo dT priming according to the manufacturer's protocol.

\section{Quantitative real-time polymerase chain reaction}

Two different quantitative PCR (qPCR) protocols were used. First, qPCR was performed using a Rotor-Gene Q (Qiagen, Hilden, Germany) with PerfeCTa MultiPlex qPCR SuperMix (Quanta Bioscience, Inc., Gaithersburg, MD, USA). The samples were run in triplicate in $10 \mu$ reactions with $1 \mu \mathrm{l}$ of the cDNA synthesis reaction together with six different sets of primers and fluorescent probes at $300 \mathrm{nM}$ concentration each. 3'6-carboxyfluorescein (FAM), 6-hexachlorofluorescein (HEX), Atto 680, Atto 390, Texas Red (Eurogentec Ltd., Fawley, Hampshire, UK), and CY5 (Sigma-Aldrich, Poole, Dorset, UK) were used as fluorochrome reporters for the probes analyzed in multiplexed reactions with six genes per run including a housekeeping gene. The reactions were performed with the following cycling conditions: $2 \mathrm{~min}$ at $95^{\circ} \mathrm{C}$, then 45 cycles of $10 \mathrm{~s}$ at $95^{\circ} \mathrm{C}$ and $60 \mathrm{~s}$ at $60^{\circ} \mathrm{C}$. Data were collected and analyzed by Rotor-Gene Q Series Software. Gene target Ct (cycle threshold) values were normalized to the HPRTI internal control. Ct values were converted to transcript quantity using standard curves obtained by serial dilution of PCRamplified DNA fragments of each gene. The linear dynamic range of the standard curves covering six orders of magnitude (serial dilution from $3.2 \times 10^{-4}$ to $8.2 \times 10^{-10}$ ) gave PCR efficiencies between 93 and $103 \%$ for each gene with $\mathrm{R}^{2}>0.998$.

In a second set of experiments, the expression of $D D B 2$, cyclin $\mathrm{G} 1$ (CCNG1), the $\mathrm{C}-\mathrm{C}$ motif chemokine ligand 3 (CCL3), the interleukins (IL)-1 $\beta$ (ILIB), IL6, IL8, and tumor growth factor $\beta 1$ (TGFB1) was analyzed with a different qPCR procedure, namely SyBr Green-based realtime PCR assay. For these genes, amplification was performed in a C100 Thermal Cycler (BioRad, Marnes-la-Coquette, France) equipped with a CFX 384 Real-Time System. Samples were run in triplicate $10 \mu \mathrm{L}$ reactions containing $5 \mu \mathrm{L}$ of LuminoCT SYBR Green qPCR ReadyMix (Sigma-Aldrich), $2 \mu \mathrm{M}$ of each primer, and $2 \mu \mathrm{L}$ of $1 / 8$ th-diluted cDNA. After $2 \mathrm{~min}$ of denaturation at $95^{\circ} \mathrm{C}$, reactions were performed for 40 cycles consisting of $5 \mathrm{~s}$ of denaturation at $95^{\circ} \mathrm{C}$ and $20 \mathrm{~s}$ of elongation at $60^{\circ} \mathrm{C}$. A melting curve was established at the end of the run to verify the amplification of a unique product in each well. Amplification curves were analyzed with the CFX Manager 3.1 software (BioRad). $\mathrm{Cq}$ for each PCR product was determined using the regression mode. Expression of each gene, corrected for primer efficiency, was normalized to the expression of HPRT and $36 B 4$ housekeeping genes amplified concurrently on the same plate [21]. PCR runs were validated when amplification of these genes resulted in $\mathrm{CV}<0.25$ and $\mathrm{M}<0.5$ values. The efficiency of the different primer pairs was between 87 and $105 \%$. The sequence of primers is provided in Table 2 . 
Table 2 Oligonucleotide primers used in this study

Oligonucleotide primers used in multiplex TaqMan assay

\begin{tabular}{|c|c|}
\hline$\overline{H P R T 1}$ & $\begin{array}{l}\text { F: 5' TCAGGCAGTATAATCCAAAGATGGT 3' } \\
\text { R: 5' AGTCTGGCTTATATCCAACACTTCG 3' } \\
\text { probe: 5' CGCAAGCTTGCTGGTGAAAAG- } \\
\text { GACCC 3' }\end{array}$ \\
\hline$D D B 2$ & $\begin{array}{l}\text { F: 5' GTCACTTCCAGCACCTCACA 3' } \\
\text { R: 5' ACGTCGATCGTCCTCAATTC 3' } \\
\text { probe: 5' AGCCTGGCATCCTCGCTACAACC' } \\
\text { 3' }\end{array}$ \\
\hline$G A D D 45$ & $\begin{array}{l}\text { F: 5' CTGCGAGAACGACATCAAC 3' } \\
\text { R: 5' AGCGTCGGTCTCCAAGAG 3' } \\
\text { probe: 5' ATCCTGCGCGTCAGCAACCCG 3' }\end{array}$ \\
\hline SESN1 & $\begin{array}{l}\text { F: 5' GCTGTCTTGTGCATTACTTGTG 3' } \\
\text { R: CTGCGCAGCAGTCTACAG 3' } \\
\text { probe: 5' ACATGTCCCACAACTTTGGT- } \\
\text { GCTGG 3' }\end{array}$ \\
\hline FDXR & $\begin{array}{l}\text { F: 5' GTACAACGGGCTTCCTGAGA3' } \\
\text { R: 5' CTCAGGTGGGGTCAGTAGGA 3' } \\
\text { probe: 5' CGGGCCACGTCCAGAGCCA 3' }\end{array}$ \\
\hline$M D M 2$ & $\begin{array}{l}\text { F: 5' CCATGATCTACAGGAACTTGGTAGTA } \\
\text { 3' } \\
\text { R:5' ACACCTGTTCTCACTCACAGATG 3' } \\
\text { probe: 5' CAATCAGCAGGAATCATCG- } \\
\text { GACTCAG 3' }\end{array}$ \\
\hline \multicolumn{2}{|c|}{ Oligonucleotide primers used in SYBR Green assay } \\
\hline HRPT1 & $\begin{array}{l}\text { S: 5' ATGGACAGGACTGAACGTCTTGCT 3, } \\
\text { R: 5' TTGAGCACACAGAGGGCTACAATG 3, }\end{array}$ \\
\hline $36 B 4$ & $\begin{array}{l}\text { S: 5' GAAATCCTGGGTGTCCGCAATGTT 3', } \\
\text { R: 5' AGACAAGGCCAGGACTCGTTTGTA 3, }\end{array}$ \\
\hline CCNG1 & $\begin{array}{l}\text { F: 5', GGAGCTGCAGTCTCTGTCAAG 3' } \\
\text { R: 5' TGACATCTAGACTCCTGTTCCAA 3, }\end{array}$ \\
\hline$D D B 2$ & $\begin{array}{l}\text { F: 5' GTCACTTCCAGCACCTCACA 3, } \\
\text { R: 5' ACGTCGATCGTCCTCAATTC 3' }\end{array}$ \\
\hline$I L 1 B$ & $\begin{array}{l}\text { F: 5' CTCGCCAGTGAAATGATGGCT 3', } \\
\text { R: 5' GTCGGAGATTCGTAGCTGGAT 3' }\end{array}$ \\
\hline IL6 & $\begin{array}{l}\text { F: 5' CCTCGACGGCATCTCAGCCCT 3' } \\
\text { R: 5' TCTGCCAGTGCCTCTTTGCTGC 3, }\end{array}$ \\
\hline IL8 & $\begin{array}{l}\text { F: 5' TGGCAGCCTTCCTGATTTCT 3', } \\
\text { R: 5' ATTTCTGTGTTGGCGCAGTG 3' }\end{array}$ \\
\hline CCL3 & $\begin{array}{l}\text { F: 5' GACCGCCTGCTGCTTCAGCTA 3, } \\
\text { R: 5' CACAGACCTGCCGGCTTCGC 3' }\end{array}$ \\
\hline$T G F B 1$ & $\begin{array}{l}\text { R: 5' GGAAATTGAGGGCTTTCGCC 3' } \\
\text { R: 5' CCGGTAGTGAACCCGTTGAT 3' }\end{array}$ \\
\hline
\end{tabular}

\section{Immunophenotyping}

Immunophenotyping of whole blood samples of the patients was performed before and after IMRT and SABR as previously described [22, 23]. Briefly, direct antibody staining of whole blood samples was performed without previous isolation of peripheral blood mononuclear cells. This allows detection of all circulating immune cells including the granulocytic compartment with multicolor flow cytometry and also reduces the required preparation steps. We here used the IPT5 assay with four measuring tubes, focusing on absolute cell count, general immune status, $\mathrm{T}$ cells, and dendritic cells in more detail. In sum, 130 immune cell characteristics were measured, including major subsets, further subsets in counts, and activation markers in percentages. The following antibodies conjugated to the indicated fluorochromes were used for the stainings: CD4PCC5.5, CD45-PECy7, CD45RA-PECy7, CD16 (B73.1)PE, CD56-FITC, CD11c-V450, CD20-PCC5.5, CD19PCC5.5, CD28-BB515, CD69-BV421, CD25-PCF594, CD80- PECy7, CD86-PECF594, PD-1-BV421, CD8-FITC, CD19-FITC, CD152-APC, CD197-PE, CD14-FITC, CD3FITC, CD274-PE, CD20-FITC, CD123-PCC5.5, CD279APC, CD123-APC, CD16 (3G8)-PE, CD4-APC, CD56APC-R700 (all BD Biosciences, Heidelberg, Germany); HLA-DR-KO, CD3-KO (all Beckman Coulter, Krefeld, Germany); CD8-PCC5.5, CD14-PCC5.5, CD25-PE-D594, CD86-PED594 (all BioLegend, Biozol, Eching, Germany); CD127-PE-Vio770, HLADR-APC-Vio770 (all Miltenyi Biotec, Bergisch Galdbach, Germany).

\section{Serum metabolome analysis}

Serum samples $(10 \mu \mathrm{L})$ were analyzed by a targeted quantitative approach using a combined direct flow injection and liquid chromatography (LC) tandem mass spectrometry (MS/MS) assay AbsoluteIDQ 180 kit (Biocrates, Innsbruck, Austria) according to the patented manufacturer's protocol described in more detail previously [24]. The method combines derivatization and extraction of analytes with selective mass spectrometric detection using multiple reaction monitoring and integrated isotope-labeled internal standards absolute quantification. This strategy allows simultaneous quantification of 185 metabolites: 40 amino acids and biogenic amines, 40 acylcarnitines, 90 glycerophospholipids, and 15 sphingomyelins (Supplementary Table 2). Mass spectrometry analyses were carried out on a TSQ Vantage EMR (Thermo SCIENTIFIC) equipped with a Surveyor HPLC system (Thermo SCIENTIFIC) using an Agilent Zorbax Eclipse XDB-C18 $(3.5 \mu \mathrm{m}) 3.0 \times 100 \mathrm{~mm}$ column and controlled by Xcalibur 2.1. software. The acquired data were processed using Xcalibur 2.1. and MetIDQ (Biocrates Life Sciences AG) software. Concentrations of all metabolites were calculated in $\mu \mathrm{M}$. To assess the significance of changes between consecutive samples of each patient, the paired $t$-test was employed with $p<0.05$ as the significance level.

\section{Human cytokine antibody array analysis}

The Proteome Profiler Human XL Cytokine Array Kit (R\&D Systems, Lille, France) allows simultaneous quantification of 105 cytokines and inflammatory mediator proteins in one sample. Membranes were hybridized using $200 \mu \mathrm{L}$ of patient serum according to the manufacturer's 
guidelines. The arrays were imaged together using the Chemidoc $^{\mathrm{TM}}$ MP imaging system (Bio-Rad). Quantification of signal intensity was performed using ImageLab Version 4.0.1 software (Bio-Rad). The values of duplicate spots representing one protein were averaged, and the background signal was subtracted.

Data for each array were then normalized to the positive control signals to adjust for between-plate effects. Each background-subtracted intensity signal was multiplied by a normalization factor defined as the ratio of the average signal intensity of the positive control spots on all analyzed arrays to the average signal intensity of the positive control spots located on the particular array being normalized. Results are illustrated as mean signal (pixel) intensity for a given protein in each sample. Negative normalized signal intensities were considered as undetected. Due to the very low quality of an array for IMRT sample D (only $20 \%$ of antibodies detected), all arrays for that patient were filtered out from further analysis. Subsequently, antibodies which were detected on at least 28 arrays (93\% of all arrays) were chosen for further continuous data analysis, resulting in 48 antibodies to analyze. Data imputation for six missing measurements was performed using the kNN algorithm with $\mathrm{k}=1$ and Euclidean distance to obtain a balanced design. Finally, the measurements for 48 antibodies on 28 arrays (7 patients) were further analyzed, following the basic pipeline described below.

\section{Data analysis}

\section{The basic data analysis pipeline}

All statistical analyses were performed on normalized data. Classical statistical inference was supported by the effect size analysis to minimize the impact of small sample size and low power of statistical tests $[25,26]$. Effect size, unlike a significance test, is independent of sample size. We applied restrictive thresholds of at least large effect size for reporting differences between subjects under comparison, to minimize the small-sample impact.

In the case of between-therapy comparisons, the MannWhitney U test was performed with the Benjamini-Hochberg correction for multiple testing. A Wendt's rank-biserial coefficient of correlation [27] (denoted as $r_{U}$ ) was calculated to estimate the effect size.

For time/dose series analysis, the repeated-measures analysis of variance (ANOVA) test for paired observations was performed. Post-hoc analysis was performed using a modified Tukey honest significant difference (HSD) test with correction for paired observations. To quantify the effect size, Cohen's d for paired observations [25] (further denoted as d) was computed. In the case of immunophenotyping data, a nonparametric Wilcoxon test for paired data was performed with corresponding rank-biserial correlation $r_{\mathrm{W}}$ calculation as a measure of effect size [28].

Linear interpolation for IMRT samples was performed to estimate the putative signal values at dose points of $7.25 \mathrm{~Gy}$ and $36.25 \mathrm{~Gy}$, which allowed for cross-therapy dose-space unification. Linear regression for known dose points was performed, and the obtained model served as the reference for signal estimation (i.e., in the case of a 7.25 Gy value approximation, a linear model between $0 \mathrm{~Gy}$ and $10 \mathrm{~Gy}$ measurements was constructed). Subsequent statistical analysis of measurements in common dose points was analogous to the one described above.

\section{Effect size interpretation}

Cohen's d effect size values $\geq 1.2$ were interpreted as indicating at least a very large effect [25], and the values $\geq 0.8$ as the evidence for at least a large effect. In the case of effect size measured by rank-biserial coefficients of correlation (both $r_{U}$ and $r_{W}$ ), the critical value for at least a large effect was set to 0.5 . The effect size quantification was done for the absolute values of the relevant statistics. Large and very large effect size values indicate differences with a very high level of confidence. For example, an at least large effect size-Cohen's $d \geq 0.8$-implies that at least $79 \%$ of observations from one group will have a higher value than the mean of the second group.

Data analysis and visualization was performed in R [29].

\section{Results}

\section{Gene expression profile of stress-responsive and cytokine genes in blood cells during RT}

First, the expression profiles of five key radiation-responsive genes (FDXR, SESN1, GADD45, DDB2, and MDM2) during the course of RT in the blood of 8 prostate cancer patients (Table 1) treated with IMRT (Fig. 2a) and SABR (Fig. 2b) were analyzed. The expression of FDXR and $D D B 2$ was found to increase in both RT treatment modalities (Fig. 2). These two genes were upregulated after the first five fractions (sample B, Fig. 2a) in patients treated with IMRT and their expression went back to background levels at the end of the therapy. The expression of FDXR and DDB2 was also upregulated in SABR patients, but here most pronounced in sample $\mathrm{C}$, i.e., at the end of the treatment (Fig. 2b). In contrast, SESN1, MDM2, and $G A D D 45$ expression levels were only slightly altered during the course of the treatment when compared to the pretherapy samples (Fig. 2).

Additionally, modulation of the expression of a different set of selected genes from the same RNA samples but 
a
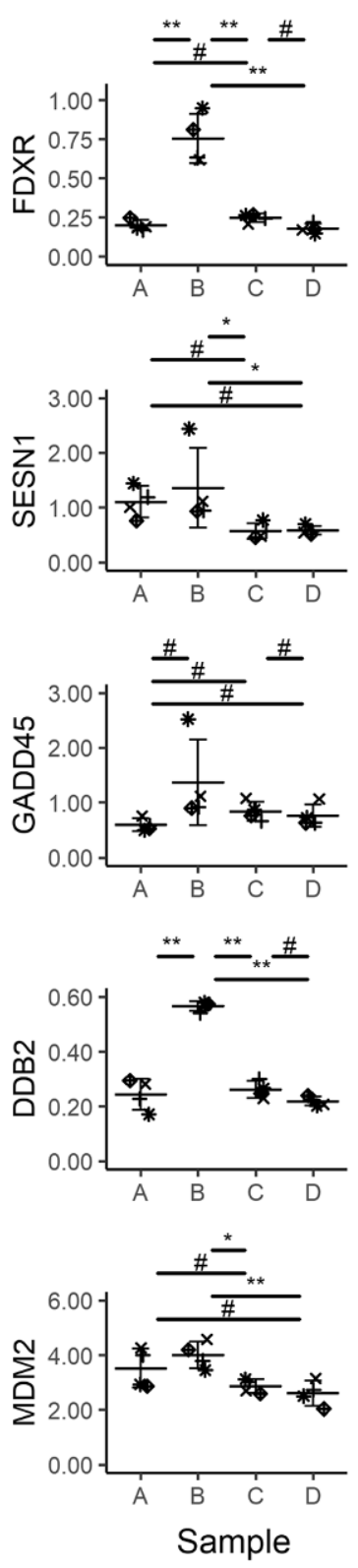

b SABR
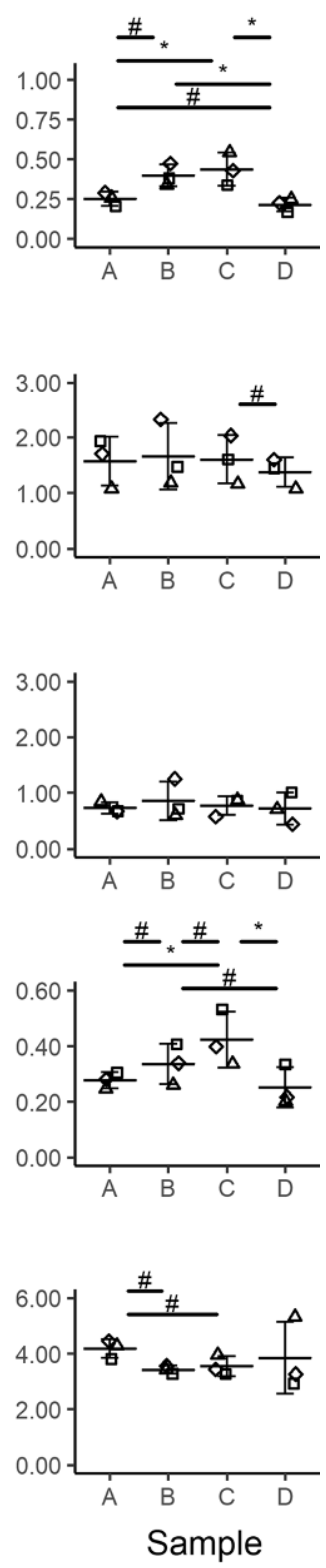

Patient + IMRT-1 $\times$ IMRT-2 $*$ IMRT-3 $\bullet$ IMRT-4 a SABR-1 $\triangle$ SABR-3 $\diamond$ SABR-4

Fig. 2 Gene expression of FXDR, SESN1, GADD45, DDB2, and $M D M 2$ in blood of prostate adenocarcinoma patients treated with IMRT (a) and SABR (b), respectively. Blood was collected before the start of the treatment (blood collection point $A$ ), after 5 fractions for the IMRT group and after the first for the SABR group (blood collection point $B$ ), after the last fraction (blood collection point $C$ ), and 1 month after the last fraction (blood collection point $D$ ). Data are shown as individual datapoints together with the mean \pm SD. Significant $p$-values for the Tukey honest significant difference (HSD) test: Asterisk for $p<0.05$ and double asterisk for $p<0.01$; hash indicates a very large effect size ( $|\mathrm{d}| \geq 1.2)$. All comparisons found significant by the Tukey HSD test also show large or very large effect sizes, which is not shown on the graph for reasons of clarity with a different RT-qPCR assay was investigated. First, to validate radiation-induced changes in the expression of the target genes of interest with a more classical SyBr Green qPCR assay, the expression of $D D B 2$ was reanalyzed in this experimental system. A similar expression profile to that obtained with the multiplex TaqMan assay for $D D B 2$ in IMRT and SABR patients was observed (Fig. 3a, b), i.e., a peak of expression in fractions $\mathrm{B}$ and $\mathrm{C}$, respectively $(p<0.05$ and effect size values $|\mathrm{d}|>1.8)$. Following this validation, the expression of genes coding for a selection of cytokines was analyzed in these samples, together with the gene coding for cyclin G1 as a second stressresponsive gene. $C C N G 1$ expression was found to be significantly higher in sample $C$ when compared to samples $B$ and D (Fig. 3b) in SABR patients ( $|\mathrm{d}|>2.1)$ but not in IMRT patients (Fig. 3a).

Expression of the $T G F B 1$ gene, coding for a cytokine with anti-inflammatory properties, was found to be increased in IMRT patients when compared to pre-RT levels. This modulation was not observed in SABR patients. Similarly, expression of the pro-inflammatory cytokine $I L I B$ gene was induced during the course of treatment and stayed high in the following weeks when compared to the pretherapy sample, but only in IMRT patients $(\mathrm{d}<-1.4$ for all pairwise comparisons). In contrast, a decrease in expression of the gene coding for the $\mathrm{C}-\mathrm{C}$ motif chemokine ligand 3 (CCL3), an inflammatory factor involved in recruitment and activation of granulocytes, during RT between samples B and $\mathrm{C}$ was observed only in SABR patients. Expression of IL6, coding for a pro-inflammatory mediator with multiple activities, and $I L 8$, another chemokine involved in neutrophils recruitment, was consistently detected only in IMRT and SABR patients, respectively. The expression of IL6 was increased in both samples $\mathrm{B}$ and $\mathrm{C}$ when compared to the pretherapy sample $(\mathrm{d}<-1.2 ;$ Fig. 3a).The expression of $I L 8$ was reduced after the first fraction (sample A vs. sample B) and during the SABR treatment (sample B vs. sample C). The IL8 mRNA level then increased again in the weeks following RT completion, but without reaching pre-RT levels (Fig. 3b).

However, one should consider that the total dose received and the number of fractions are different in IMRT and SABR patients at samples B and C. These differences may explain the different gene expression patterns observed for, e.g., $D D B 2$. To take this into account, gene expression values were approximated for IMRT patients for the radiation doses $7.25 \mathrm{~Gy}$ and $36.25 \mathrm{~Gy}$, corresponding to SABR fractions $\mathrm{B}$ and $\mathrm{C}$. The expression of $D D B 2$ was again found to be higher than in the sample before RT, both after $7.25 \mathrm{~Gy}$ $(p$-value $=0.001, \mathrm{~d}=-4.9)$ and $36.25 \mathrm{~Gy}(p$-value $=0.002$, $\mathrm{d}=-6.7$ ) "virtual-doses" (Fig. 4). Importantly, in this interpolation, there is a similar level of expression of $D D B 2$ in IMRT and SABR patients at the dose of $36.25 \mathrm{~Gy}$ ( $p$ - 
a
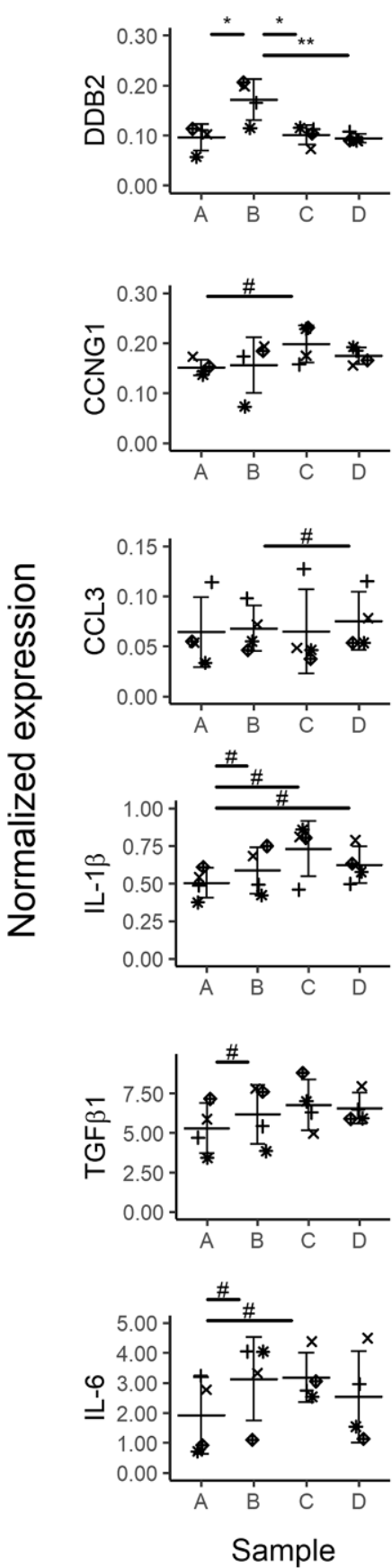

b SABR
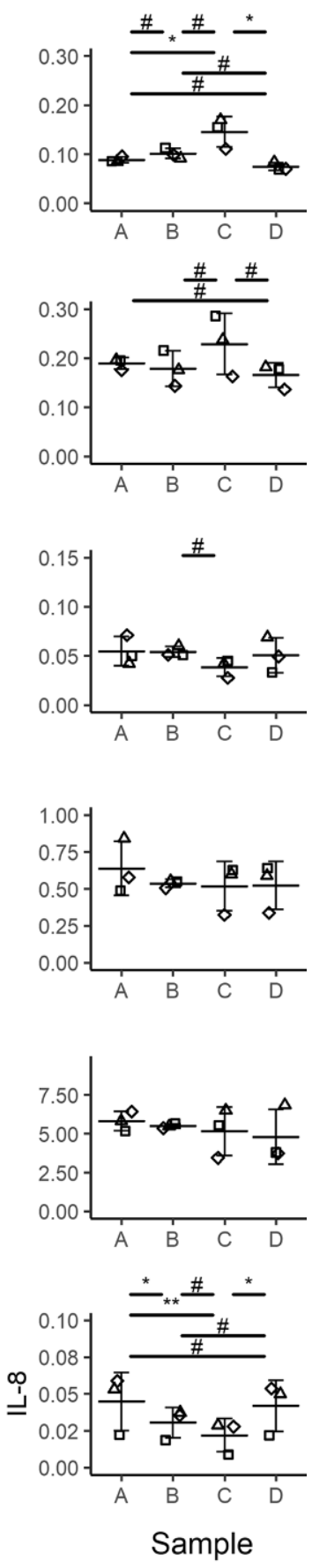

Patient + IMRT-1 $\times$ IMRT-2 * IMRT-3 $\bullet$ IMRT-4 a SABR-1 $\triangle$ SABR-3 $\diamond$ SABR-4

Fig. 3 Gene expression of $C C N G 1, D D B 2, C C L 3, I L 1 B, T G F B 1$, and $I L 6$ or $I L 8$ in blood of the prostate adenocarcinoma patients treated with IMRT (a) and SABR (b). Blood was collected before the start of the treatment (blood collection point $A$ ), after 5 fractions for the IMRT group and after the first for the SABR group (blood collection point $B$ ), after the last fraction (blood collection point $C$ ), and 1 month after the last fraction (blood collection point $D$ ). Data are shown as individual datapoints together with the mean \pm SD. Significant $p$-values for Tukey honest significant difference (HSD) test: asterisk for $p<0.05$ and double asterisk for $p<0.01$; hash indicates a very large effect size $(\mid \mathrm{d} l \geq 1.2)$. All comparisons found significant by the Tukey HSD test also show large or very large effect size, which is not shown on the graph for reasons of clarity

value $=0.875, r_{U}=0.2$, data not shown), suggesting that the total dose received might be the main parameter driving radiation-induced gene expression. Also, the expression of $T G F B 1$ was upregulated after $7.5 \mathrm{~Gy}$ and $36.25 \mathrm{~Gy}$ when compared to pre-RT values (Fig. 4). ILIB gene expression was also significantly increased (Fig. 4). Furthermore, effect size statistics suggest that the expression after $36.5 \mathrm{~Gy}$ is higher than after $7.25 \mathrm{~Gy}$, even if this effect is not as strong for TGFBI $(\mathrm{d}=-0.9)$ as for IL-1 $\beta(\mathrm{d}=-1.4)$. Altogether, these observations and calculations suggest that the expression of $I L I B$ and $T G F B I$ genes is progressively induced during IMRT.

We additionally compared the modulation of inflammatory gene expression in both therapies. Pairwise comparison of the normalized gene expression values in the different samples by a Mann-Whitney U test did not show any significant difference. However, the finding of large effects sizes ( $\left.\left|\mathbf{r}_{U}\right| \geq 0.5\right)$ between certain pairs of samples suggests that cytokine gene expression is differentially modulated during IMRT and SABR. As shown in Table 3, a higher expression level of $C C L 3$ and TGFB1 genes for IMRT patients as compared to SABR patients in samples $C$ and $D$ was observed, while this was not the case in samples A and B $\left(\left|r_{U}\right|<0.5\right)$. These results indicate that IMRT treatment induces a stronger increase in $C C L 3$ and TGFB1 gene expression by the end of the RT compared to SABR. This higher level of expression is maintained in the weeks following RT completion. $I L I B$ was found to be more expressed in SABR patients in pre-RT sample A, but this difference was abrogated in sample B $\left(\left|r_{U}\right|<0.5\right)$. This trend was inverted in sample $\mathrm{C}$, where $I L 1 B$ becomes more expressed in IMRT patients. This difference disappeared in the weeks following RT completion. Thus, the expression of these three genes is clearly more induced during IMRT compared to SABR. The differential upregulation was maintained in the weeks following RT completion for CCL3 and TGFB1, while it was only transitory for $I L I B$. 

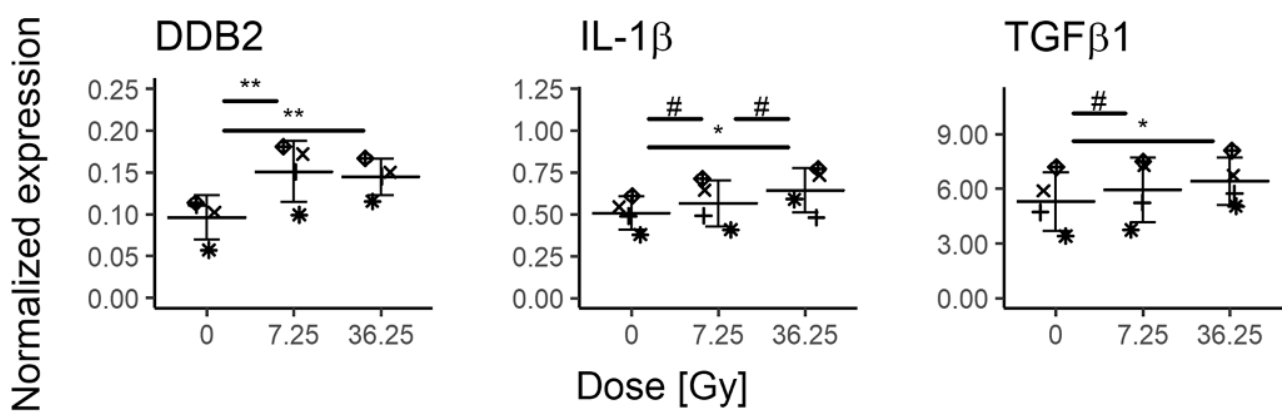

Patient + IMRT-1 $\times$ IMRT-2 $*$ IMRT-3 $\diamond$ IMRT-4

Fig. 4 Normalized gene expression values for $D D B 2, I L 1 B$, and $T G F B 1$ gene expression in IMRT patients, interpolated for radiation doses 7.25 Gy and $36.25 \mathrm{~Gy}$. Data are shown as individual datapoints together with the mean \pm SD. Significant $p$-values for the Tukey honest significant difference (HSD) test: asterisk for $p<0.05$ and double asterisk for $p<0.01$; hash indicates a very large effect size ( $|\mathrm{d}| \geq 1.2)$. All comparisons found significant by the Tukey HSD test also show large or very large effect size, which are not shown on the graph for reasons of clarity

Table 3 Comparison of cytokine gene expression in IMRT and SABR samples A-D

\begin{tabular}{llll}
\hline Target & Sample & $\begin{array}{l}\text { Mann-Whitney U } \\
p \text {-value }\end{array}$ & Wendt's effect size $\mathrm{r}_{\mathrm{U}}$ \\
\hline CCL3 & A & 0.857 & -0.167 \\
& $\mathrm{~B}$ & 0.629 & -0.333 \\
& $\mathrm{C}$ & 0.229 & $\mathbf{- 0 . 6 6 7}$ \\
& $\mathrm{D}$ & 0.229 & $\mathbf{- 0 . 6 6 7}$ \\
IL1B & $\mathrm{A}$ & 0.400 & $\mathbf{0 . 5 0 0}$ \\
& $\mathrm{B}$ & 1.000 & 0.000 \\
& $\mathrm{C}$ & 0.229 & $\mathbf{- 0 . 6 6 7}$ \\
& $\mathrm{D}$ & 0.857 & -0.167 \\
TGFB1 & $\mathrm{A}$ & 0.857 & 0.167 \\
& $\mathrm{~B}$ & 0.857 & -0.167 \\
& $\mathrm{C}$ & 0.400 & $\mathbf{- 0 . 5 0 0}$ \\
& $\mathrm{D}$ & 0.400 & $\mathbf{- 0 . 5 0 0}$ \\
\hline
\end{tabular}

Values indicating at least large effect size (ru) are indicated in bold

\section{Immunophenotyping of blood cells during RT}

Besides changes in expression of stress-responsive and cytokine genes in blood cells during RT, general cellular immune modulations might take place. Therefore, immunophenotyping of whole blood of the patients was performed. As expected for a systemic immunological response after RT, a decrease of B cells, T cells, and NK cells in the peripheral blood was observed following IMRT. However, such a decline was only observed in 2/4 patients following SABR, and in 2 patients, the neutrophils and monocytes increased following SABR. However, regarding immune-suppressive myeloid-derived suppressor cells (MDSCs), a high increase was only observed in patients who were treated with SABR. Interestingly, again only after SABR, a decrease of HLA-DR expression on monocytes was detected in all patients. One common feature of both treatments was an increased expression of the inhibitory programmed death 1 (PD-1) receptor on $\mathrm{CD} 4+\mathrm{T}$ cells (Fig. 5).

\section{Changes in metabolic products during RT}

To obtain further deeper insights in distinct systemic modulations following IMRT and SABR, 137 metabolites were quantified in sera of the cancer patients (listed in Supplementary Table 2). Differences in the abundance of selected compounds were observed in individual patients, but few remained statistically significant due to the small size of the patient group (uncorrected $p$-value $<0.05$ ). However, marked differences between IMRT and SABR patients were noted for two classes of metabolites: phosphatidylcholines (PCs) and lysophosphatidylcholines (LPCs). There were more PCs affected by RT in the IMRT group than in the SABR group (in general, $18 \%$ of detected PCs were RT affected in either group and sample). On the other hand, there were more LPCs affected by RT in the SABR group than in the IMRT group (in general, $56 \%$ of detected LPCs were RT affected; Fig. 6a). Therefore, changes in the total LPC/PC ratio in samples of individual patients were analyzed (Fig. 6b). In the SABR group, this ratio generally increased in sample B (that corresponded to the effect of a single $7.25 \mathrm{~Gy}$ dose), with a large effect size $(\mathrm{d}=-0.9)$. On the other hand, in the IMRT group, this ratio generally decreased in sample B (that corresponded to the effect of five $2 \mathrm{~Gy}$ fractions), with a very large effect size $(\mathrm{d}=1.5)$. In both cases, changes in the total LPC/PC ratio resulted from changes in levels of both LPCs and PCs. Importantly, a pairwise comparison of both therapies revealed a significant difference (effect size $r_{U}=0.75$ ) in individual changes between sample A and sample B. The LPC/LC ratio returned to the pre-RT value in the post-RT sample D that was collected 1 month after the end of treatment in IMRT patients. 
a

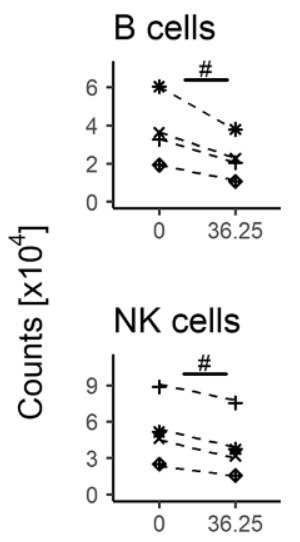

IMRT
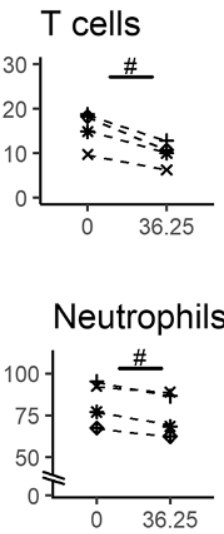

TH.PD1

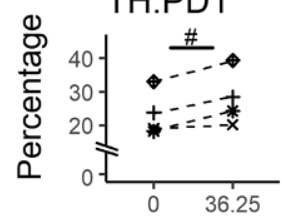

Mo.HLADR

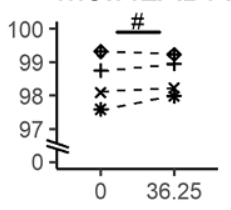

Dose [Gy] b
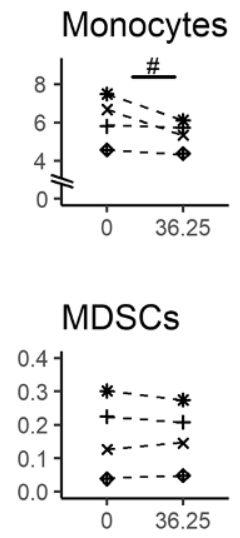

SABR
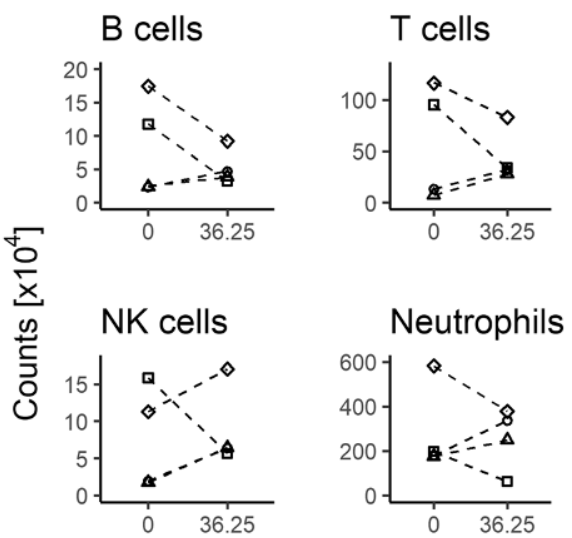

Monocytes
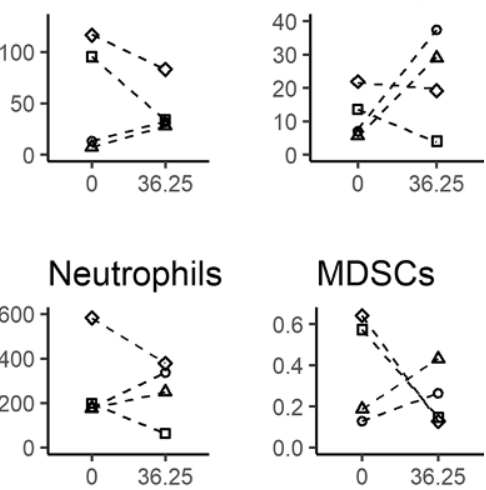

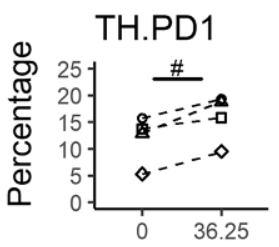

Mo.HLADR

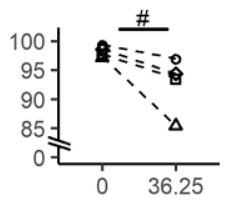

\section{Dose [Gy]}

Patient $\square$ SABR-1

- SABR-2 $\triangle$ SABR-3

$\diamond$ SABR-4

Fig. 5 Immunophenotyping of whole blood of the prostate adenocarcinoma patients treated with IMRT (a) and SABR (b). Whole blood was collected before the start of the treatment and after the last radiation fraction. Expression values were interpolated for IMRT patients for radiation dose of $36.25 \mathrm{~Gy}$ for better comparison with SABR-related values. The counts of B cells, T cells, neutrophils, natural killer (NK) cells, monocytes, and myeloid-derived suppressor cells $(M D S C s)$ per $\mathrm{ml}$ of peripheral blood are displayed as well as the percentages of HLA-DR-expressing monocytes $(M o)$ and programmed death 1 receptor-expressingT helper cells (TH.PD1). Hash indicates comparisons showing at least a large effect size $(|r w| \geq 0.5)$

a
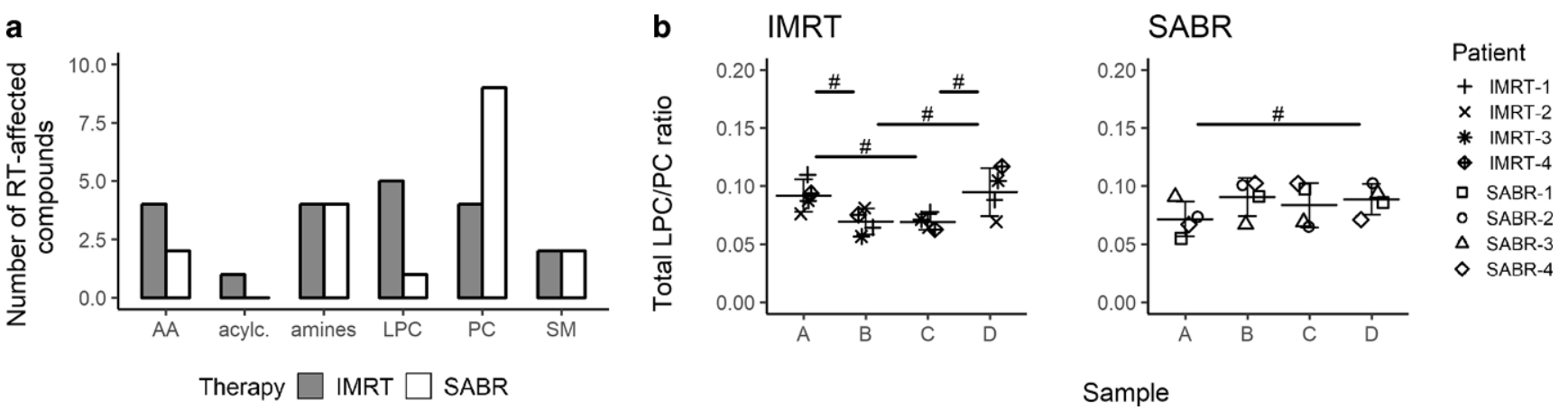

Fig. 6 Radiotherapy-related changes in serum metabolome of the prostate adenocarcinoma patients treated with IMRT and SABR. a Numbers of compounds in different classes of metabolites that changed their abundances between pre-RT sample A and either post-RT sample B, C, or D (uncorrected $p<0.05$ ). Samples from patients subjected to IMRT and SABR are compared in the following classes: phosphatidylcholines $(P C$; 67 compounds in total), lysophosphatidylcholines (LPC; 9), sphingomyelins (SM; 13), acylcarnitines (acylc.; 11), amino acids (AA; 21), biogenic amines (amines; 16). b Changes in the ratio of total LPC versus PC (LPC/PC) quantitated in sera of individual patients from both groups. Hash indicates comparisons showing at least a very large effect size $(|\mathrm{d}| \geq 1.2)$

\section{Modulation of cytokines, inflammatory proteins, and immune regulators abundance in plasma during RT}

Finally, the modulation of the level of a collection of 105 cytokines and proteins was analyzed in the serum of the cancer patients during the course of RT by using dedicated antibody arrays. This analysis was restricted to a subgroup of 48 proteins which gave a measurable signal in at least 26 of the 28 antibody arrays analyzed (one array/sample for each patient). Out of these 48 cytokines, an ANOVA test for repeated measures showed statistical differences ( $p$ - 
Table 4 Serum proteins showing very large effect sizes between at least three pairwise sample comparisons (out of six possible) during RT

\begin{tabular}{ll}
\hline SABR & IMRT \\
\hline- & BAFF \\
- & Chitinase 3-like 1 \\
- & Complement factor D \\
- & C-reactive protein \\
- & DPPIV \\
GDF-15 & GDF-15 \\
IGFBP-2 & - \\
- & IGFBP-3 \\
- & MMP-9 \\
- & RANTES \\
- & Resistin \\
- & SHBG \\
- & Thrombospondin-1 \\
- & CD31 \\
TIM-3 & TIM-3 \\
- & VCAM-1 \\
\hline
\end{tabular}

Proteins for which ANOVA $p$-value was statistically significant $(p<0.05)$ are indicated with bold.

$B A F F$ B-cell activation factor, $C D 31$ Platelet and endothelial cell adhesion molecule 1, CRP C-reactive protein, DDPIV Dipeptidyl peptidase 4, GDF-15 Growth and differentiation factor 15, IGFBP Insulin-like growth factor binding protein, $M M P 9$ Matrix metallopeptidase 9, RANTES Regulated on activation, normal $\mathrm{T}$ cell expressed and secreted, $S H B G$ Sex hormone-binding globulin, Tim-3 T-cell immunoglobulin and mucin domain-containing 3, VCAM-1 Vascular cell adhesion molecule 1

value $<0.05$ ) in the level of expression at different timepoints for only six factors (Table 4 and Supplementary Fig. 1): BAFF (B-cell activating factor), complement factor D (CFD), C-reactive protein (CRP), thrombospondin-1, and dipeptidyl peptidase 4 (DPPIV) for IMRT patients, and the soluble form of the T-cell immunoglobulin and mucindomain containing-3 receptor (Tim-3) for SABR patients.

However, further analysis showed a very large effect size $(|\mathrm{d}| \geq 1.2)$ for the expression of several other soluble factors at different timepoints during RT. To identify those modulated during the course of RT with the highest level of confidence possible in our setting, we selected only those proteins for which at least three of the six possible pairwise comparisons between the four samples resulted in very large effect sizes, indicating differences between at least three samples. This analysis resulted in the identification of an additional group of serum proteins with modulated expression during and/or after RT, as compared to the preRT sample (Table 4 and Supplementary Fig. 1). Altogether, with these criteria, 15 out of the 48 proteins detectable on the antibody array membranes were found to be modulated during IMRT, but only 3 during SABR. Only 2 proteins

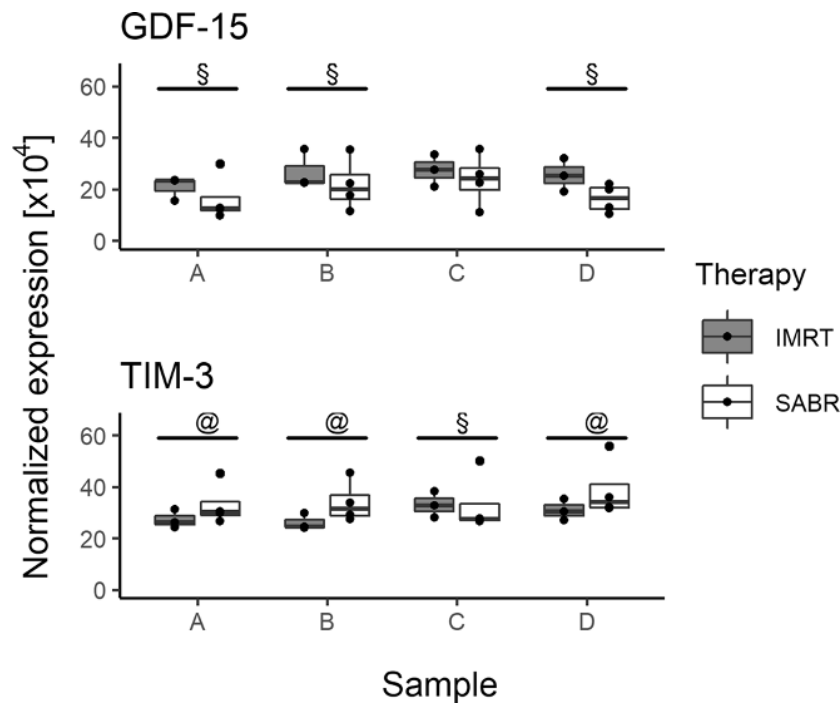

Fig. 7 Comparison of the modulation of GDF15 and TIM-3 proteins during IMRT and SABR. At least large effect sizes ( $|r u| \geq 0.5)$ were indicated with an @ and a $\S$ sign for positive and negative $\mathrm{r}_{U}$ values, respectively

were modulated in both treatments: growth and differentiation factor 15 (GDF-15) and Tim-3.

Only 3 of the 15 factors modulated during IMRT, namely CRP, GDF- 15 , and the sex hormone-binding globulin (SHBG) were found to be increased in sample B when compared to pre-RT sample A, whereas four (BAFF, CFD, DDPIV, and resistin) were decreased. The serum level of 10 of these factors (BAFF, chitinase 3-like 11, CRP, CFD, DPPIV, Insulin-like growth factor binding protein3 (IGFBP 3), matrix metallopeptides 9 (MMP9), resistin, thrombospondin-1, Tim-3) was higher in sample $\mathrm{C}$ compared to sample $\mathrm{B}$, indicating an increase in their serum concentration during the course of RT. A decrease in the level of several proteins in the weeks following RT completion were also observed. The expression of BAFF, CFD, CRP, GDF-15, IGFBP-3, SHBG, CD31, and Tim-3 was lower in sample D vs. sample C. However, for a large subgroup including BAFF, CRP, DPPIV, GDF-15, MMP9, Regulated on activation, normal $\mathrm{T}$ cell expressed and secreted (RANTES), thrombospondin-1, CD31, Tim-3, and Vascular cell adhesion molecule 1 (VCAM-1), the level of expression in sample D was higher than in sample A, indicating that the induction of the expression of these cytokines/factors is long lasting and persists at higher levels in the weeks following RT completion compared to the pre-RT samples.

Only three factors were modulated during the course of SABR. GDF-15 and IGFBP-2 already increased after the first fraction (sample B) and stayed elevated at the end of RT (sample C) when compared to pre-RT levels (sample A). Whereas the GDF-15 level decreased in the weeks following RT completion, the level of IGFBP-2 stayed elevated. 
The pattern of modulation of Tim-3 was clearly different, as its expression was elevated only in sample D, i.e., weeks after RT completion (Supplementary Fig. 1).

As GDF-15 and Tim-3 were both found to be regulated during the course of the two RT modalities, we next compared their modulation patterns (Fig. 7). A large effect size $\left(\left|r_{U}\right|>0.5\right)$ was observed for most of the timepoints. Tim-3 was expressed more highly in SABR compared to IMRT patient samples A, B, and D, but more expressed in IMRT than SABR patient samples at timepoint $C$. This pattern suggests that IMRT was able to evoke a stronger induction of Tim-3 expression than SABR during the RT procedure. This induction subsided in the weeks following the end of the treatment. For GDF-15, a mirrored pattern was observed: GDF-15 was more highly expressed in IMRT patient samples A, B, and D, but not in sample C. Thus, here, it appears that SABR induced the serum level of GDF-15 to a greater extent than IMRT.

\section{Discussion}

This exploratory study presents for the first time a detailed analysis of several stress and immune parameters at a systemic level that might be modulated in vivo following local exposure to ionizing radiation in a small group of patients treated for prostate cancer by RT using IMRT and SABR. Both RT modalities have similar anti-tumor efficiency [30] and a low level of acute toxicity was observed in our patients: only one of the IMRT patients exhibited grade 2 gastrointestinal toxicity. Therefore, the observed modulations of immune or immune-related parameters reported in this study can be considered to reflect the effects of locally applied ionizing radiation on systemic immune alterations in patients with prostate adenocarcinoma rather than differences in radiation-induced toxicity.

Overall, the exposure of IMRT and SABR patients differed in terms of the total dose delivered over the RT course, the dose per fraction, the number of fractions, the dose rate, and the irradiated CTV. Patients treated with IMRT and one patient treated with SABR received androgen-deprivation therapy. ADT has been shown to induce a rapid recruitment of T lymphocytes and antigen-presenting cells to the tumor bed [31]. ADT can also induce a rebound in the production of naïve peripheral $\mathrm{T}$ lymphocytes in prostate cancer patients [32]. However, no effects of ADT on the homeostasis of $\mathrm{B}, \mathrm{T}$, and $\mathrm{NK}$ cell subsets in the peripheral blood of treated patients were observed in a comparison of healthy donors and treated patients [33]. In this study, immunophenotyping did not reveal any specific modulation of lymphocyte populations in ADT-treated patients before or during RT. One can therefore conclude that ADT did not interfere with the analyses of systemic modulations during IMRT and SABR. The observed differences should rather result from differences in radiation volume and/or dose and/or treatment technique, including the number of fractions delivered. Because of the small size of 4 patients per treatment group, putative differences between RT modalities might be masked by inter-individual differences between patients. To circumvent this potential problem, we compared the evolution of the modulation of the different endpoints during IMRT and SABR, and not their absolute level. Furthermore, effect size values were calculated. In contrast to statistical testing, effect size does not depend on sample size and thus can provide more reliable results. The use of a restrictive threshold (at least a large effect size) allowed identification of the strongest differences and variations between samples with a high level of confidence.

In this study, a large array of stress and immune parameters at the systemic level in the blood of IMRT- and SABR-treated prostate cancer patients was analyzed. The average total dose delivered to the patients' blood during RT in the treating center (with an estimation based on the individual treatment plans, assuming that the blood volume corresponds to $8 \%$ of the irradiated body mass and that there is a homogenous vascularization of irradiated tissues) was $0.035 \mathrm{~Gy}$ per $100 \mathrm{~mL}$ and $0.009 \mathrm{~Gy}$ per $100 \mathrm{~mL}$ in the case of IMRT and SABR patients, respectively. Because of the specificities of IMRT and SABR, samples B and C correspond to different treatment doses and durations. In an attempt to directly compare the effects of these two treatment modalities for the same dose, we interpolated values obtained in IMRT patients in samples B and $\mathrm{C}$ to equivalent radiation doses (i.e., 7.25 and $36.25 \mathrm{~Gy}$ ).

A large body of work has been devoted to the identification of biomarkers of radiation exposure. The level of transcription of selected p53-dependent genes was shown to be a good candidate for both total and partial body exposure over a wide range of ionizing radiation doses [34]. Data on the systemic effects of IMRT and SABR are, however, still scarce. Our analyses revealed a transient increase in the expression of $F D X R$ and $D D B 2$ in both IMRT and SABR patients during the course of RT, with, however, different kinetics. These different kinetics might be related to the total dose delivered at each specific blood collection timepoint and/or to the exposed volume. Interpolating the putative expression levels obtained in IMRT patients to similar doses delivered in SABR suggests that $D D B 2$ transcription is induced in both treatments already after $7.25 \mathrm{~Gy}$. It further increases until a cumulative dose of $36.25 \mathrm{~Gy}$, suggesting similar induction mechanisms during the course of SABR and IMRT treatments.

In contrast, the effects of local radiation exposure on immune parameters at the cellular and humoral levels were different in patients treated with IMRT and SABR. The induction of transcription of $I L I B$ and $T G F B I$ genes took 
place only in IMRT patients. Generally, IMRT resulted in modulation of a much larger number of cytokines and proteins in the serum compared to SABR. Evolution of the LPC/PC ratio, a postulated metabolomic indicator of inflammation $[19,20]$, was strikingly different during the course of IMRT and SABR. Altogether, these observations suggest that inflammatory mechanisms are differentially regulated during the course of IMRT and SABR. In contrast, the effects of RT on the expression of certain activation markers in circulating immune cell subsets was very homogeneous. In all patients, an increase in the percentage of PD-1-expressing CD4 ${ }^{+} \mathrm{T}$ lymphocytes was for example observed at the end of the treatment.

The impact of even low doses of ionizing radiation on the expression of activation markers by immune cell subsets has already been observed [9]. Modulation of antitumor immune responses by interfering with PD-L1/PD-1 interactions has systemic effects on the T cell compartment. Thus, an increase in circulating PD- $1^{+} \mathrm{CD} 4^{+} \mathrm{T}$ cells (and in myeloid-derived suppressor cells) following RT completion was, for example, associated with reduced T cell activity in colorectal cancer patients [35]. However, on the other hand, RT can also result in an increased frequency of circulating tumor-specific $\mathrm{T}$ cells in the $\mathrm{CD} 8^{+}$population, as observed in colorectal and prostate cancer patients [36], and the frequency of circulating HLA-DR ${ }^{\text {hi }}$ monocytes is a strong predictor of progression-free and overall survival in response to therapy in stage IV melanoma patients [37]. It was already described in 1999 that even though RT reduces immune cell numbers in the peripheral blood, the remaining lymphocyte function was still within the normal range [38]. Our findings confirm such immune modulations in prostate adenocarcinoma patients. In addition, the results of this explorative study provide-for the first time-indications that different RT protocols and application methods such as IMRT and SABR modulate several components of the immune system differently, as well as their dynamics. Interestingly, in patients treated with IMRT, changes in the level of BAFF, a survival factor of B cells, correlated with absolute numbers of B cells. Thus, local radiation exposure partially exerts its systemic effects by altering immune cell subsets, their activation status, and also their microenvironment.

The immunological consequences of DNA damage are becoming more and more evident [39]. Interestingly, during IMRT, expression of the $D D B 2$ gene appears to be already increased after $7.25 \mathrm{~Gy}$, whereas induction of the expression of $I L I B$ and TGFBI genes in the same samples is only evident after $36.25 \mathrm{~Gy}$. Similarly, the serum concentration of the inflammatory cytokines and proteins modulated during IMRT was mostly upregulated only between samples B and C, but not in sample B compared to the pre-RT sample A. This delay in the induction of stress-response genes and of inflammatory parameters in the peripheral blood cells suggests that these events are differentially regulated in blood cells with individual dynamics. It may be that inflammatory genes are not directly induced by radiation, but rather that their up-regulation is a consequence of the biological effects elicited by radiation exposure, namely tumor cell death and the death of at least a fraction of irradiated circulating blood cells [40]. Irrespective of their identity, these mechanisms and their outcome(s) are complex, as shown by the findings that both IL-1 $\beta$, a prototypic pro-inflammatory cytokine, and TGF $\beta 1$, a prototypic anti-inflammatory cytokine, were coregulated during IMRT. Another example is the coregulation of the chemokine RANTES and of the exopeptidase DDPIV, as proteolytic cleavage of RANTES by DDPIV can modulate its activity. The simultaneous upregulation of effectors with opposing activities indicates that radiation-induced stress and immune effects are multifaceted. The balance of these activities is finely regulated during the responses elicited by IMRT and SABR. In the rare cases of a similar factor being modulated in patients treated with either IMRT or SABR, this modulation appears to be in opposite directions in the different RT modalities, as shown in our study of GDF-15 and Tim-3. GDF-15 is a member of the TGF $\beta$ family with both pro- and anti-tumor activities [41]. Its expression is associated with cellular stress conditions like irradiation in human PBLs [42], primary fibroblasts exposed ex vivo [43, 44], and murine splenocytes following whole-body exposure [45]. Our results now show that it is also transiently induced in vivo during RT, with specific regulation in each RT modality. This difference may be linked to the different initial levels of GDF-15 in both groups of patients, or to differences in cell death/stress or tissue damage. We did indeed observe regulation of several factors denoting endothelial dysfunction (CD31, VCAM, thrombospondin) and tissue remodeling (MMP9, chitinase 3-like 1) in IMRT, but not in SABR patients. The other differently regulated protein common to both groups of patients is Tim-3, a negative regulator of Th lymphocytes and innate immune cell activation when expressed on the cell surface [46]. In vitro, Tim-3 has been found to be shed by ADAM proteases from the surface of human TLR-activated CD14+ monocytes [47, 48]. Here, we observed a low but detectable persistent increase in the circulating level of Tim-3 in the weeks following the end of the treatment in both IMRT and SABR patients. So far, no function has been attributed to this soluble Tim-3 protein, but its increase may reflect innate immune cell activation during IMRT and SABR treatments.

Even though this explorative study was already quite comprehensive, future studies should be even more detailed and include more immune parameters such as danger signals that reflect radiation-induced immune damage response [49] or HSP70 abundance [50], which give indications about the tumor status. 
In addition, future studies should also consider additional endpoints such as DNA damage, including complex and oxidative lesions, apoptosis, the use of sensitive methods such as enzyme-linked immunosorbent assay (ELISA) to measure the modulation of circulating inflammatory cytokines, and of course clinical outcome. The level of a collection of cytokines was found to be differentially regulated in lung cancer patients treated by RT only vs. patients treated with $\mathrm{RT}+$ chemotherapy, and the early modulation of some of these cytokines was correlated with lung toxicity [15]. It was also shown that DNA damage could be detected in non-irradiated, out-of-field tissues in a different cohort of patients treated by RT or RT + chemotherapy for lung cancer [51]. This abscopal effect is similarly observed in preclinical mouse models locally exposed to a single dose of high-dose-rate synchrotron radiation $[52,53]$. In mice, the generation of genotoxic lesions at distant sites was found to depend on a functional immune system and was attenuated in the absence of the CCL2/MCP-1 cytokine. It would be interesting to find out whether the different modulation of immune parameters that we observe in IMRT and SABR patients translates into a differential pattern of genotoxic stress at distant sites according to RT modality in patients. Pre-clinical mouse studies could be designed to investigate the eventual relations between dose, dose rate, repeated exposure, immune modulation, and genotoxic effects at distant sites in the context of local irradiation of normal tissue or tumors.

In conclusion, the data presented herein depict that localized irradiation results in systemic modulation of a large range of cellular and humoral immune parameters. The radiation-induced effects on inflammatory gene transcription, immune cell homeostasis, and serum concentration of lipids and cytokines appear to be different in patients treated by different RT modalities. These differences are qualitative (e.g., genes induced only in IMRT, more cytokines modulated in IMRT, myeloid cells modulated only in SABR) and quantitative (e.g., different evolution of LPC/PC ratio). This exploratory study suggests that RT modalities with similarly high therapeutic efficiency and low clinical toxicity can have different effects on immune system homeostasis and activation at the systemic cellular and molecular level for up to 5 weeks following RT completion. Late effects of $\mathrm{RT}$ such as a decrease in circulating $\mathrm{CD}^{+} \mathrm{T}$ lymphocytes have previously been observed in prostate cancer patients 12 months post treatment [54]. Thus, the findings presented here need to be confirmed in larger groups of patients in the future, also taking into account further analyses at even later timepoints after completion of RT.

Funding This work received funding from the European Union's Seventh Framework Programme from the OPERRA project (Euratom/FP7) under grant agreement No. 604984604984 and from the European Social Fund grant POWR.03.02.00-00-I029 (JM). This work has also been supported by National Science Centre, Poland NCN BiTIMS grant no. 2015/19/B/ST6/01736 (JP) and by the German Federal Ministry of Education and Research (BMBF; GREWIS-alpha, 02NUK050E) (BF and UG).

Conflict of interest B. Frey, J. Mika, K. Jelonek, L. Cruz-Garcia, C. Roelants, I. Testard, N. Cherradi, K. Lumniczky, S. Polozov, A. Napieralska, P. Widlak, U.S. Gaipl, C. Badie, J. Polanska, and S.M. Candéias declare that they have no competing interests.

Open Access This article is licensed under a Creative Commons Attribution 4.0 International License, which permits use, sharing, adaptation, distribution and reproduction in any medium or format, as long as you give appropriate credit to the original author(s) and the source, provide a link to the Creative Commons licence, and indicate if changes were made. The images or other third party material in this article are included in the article's Creative Commons licence, unless indicated otherwise in a credit line to the material. If material is not included in the article's Creative Commons licence and your intended use is not permitted by statutory regulation or exceeds the permitted use, you will need to obtain permission directly from the copyright holder. To view a copy of this licence, visit http://creativecommons.org/licenses/by/4. $0 /$.

\section{References}

1. Orth M, Lauber K, Niyazi M, Friedl AA, Li M, Maihofer C, Schuttrumpf L, Ernst A, Niemoller OM, Belka C (2014) Current concepts in clinical radiation oncology. Radiat Environ Biophys 53(1):1-29. https://doi.org/10.1007/s00411-013-0497-2

2. Deloch L, Derer A, Hartmann J, Frey B, Fietkau R, Gaipl US (2016) Modern radiotherapy concepts and the impact of radiation on immune activation. Front Oncol 6:141. https://doi.org/10.3389/fonc. 2016.00141

3. Ruckert M, Deloch L, Fietkau R, Frey B, Hecht M, Gaipl US (2018) Immune modulatory effects of radiotherapy as basis for well-reasoned radioimmunotherapies. Strahlenther Onkol 194(6):509-519. https://doi.org/10.1007/s00066-018-1287-1

4. Manning G, Kabacik S, Finnon P, Bouffler S, Badie C (2013) High and low dose responses of transcriptional biomarkers in ex vivo X-irradiated human blood. Int J Radiat Biol 89(7):512-522. https:// doi.org/10.3109/09553002.2013.769694

5. Cruz-Garcia L, O'Brien G, Donovan E, Gothard L, Boyle S, Laval A, Testard I, Ponge L, Wozniak G, Miszczyk L, Candeias SM, Ainsbury E, Widlak P, Somaiah N, Badie C (2018) Influence of confounding factors on radiation dose estimation using in vivo validated transcriptional biomarkers. Health Phys 115(1):90-101. https://doi.org/10.1097/HP.0000000000000844

6. O’Brien G, Cruz-Garcia L, Majewski M, Grepl J, Abend M, Port M, Tichy A, Sirak I, Malkova A, Donovan E, Gothard L, Boyle S, Somaiah N, Ainsbury E, Ponge L, Slosarek K, Miszczyk L, Widlak P, Green E, Patel N, Kudari M, Gleeson F, Vinnikov V, Starenkiy V, Artiukh S, Vasyliev L, Zaman A, Badie C (2018) FDXR is a biomarker of radiation exposure in vivo. Sci Rep 8(1):684. https://doi.org/10.1038/s41598-017-19043-w

7. Filiano AN, Fathallah-Shaykh HM, Fiveash J, Gage J, Cantor A, Kharbanda S, Johnson MR (2011) Gene expression analysis in radiotherapy patients and C57BL/6 mice as a measure of exposure to ionizing radiation. Radiat Res 176(1):49-61. https://doi.org/10. 1667/RR2419.1

8. Manning G, Tichy A, Sirak I, Badie C (2017) Radiotherapy-associated long-term modification of expression of the inflammatory biomarker genes ARG1, BCL2L1, and MYC. Front Immunol 8:412. https://doi.org/10.3389/fimmu.2017.00412

9. Paul S, Barker CA, Turner HC, McLane A, Wolden SL, Amundson SA (2011) Prediction of in vivo radiation dose status in radio- 
therapy patients using ex vivo and in vivo gene expression signatures. Radiat Res 175(3):257-265. https://doi.org/10.1667/RR2420. 1

10. Mittal D, Gubin MM, Schreiber RD, Smyth MJ (2014) New insights into cancer immunoediting and its three component phases-elimination, equilibrium and escape. Curr Opin Immunol 27:16-25. https://doi.org/10.1016/j.coi.2014.01.004

11. Frey B, Ruckert M, Deloch L, Ruhle PF, Derer A, Fietkau R, Gaipl US (2017) Immunomodulation by ionizing radiation-impact for design of radio-immunotherapies and for treatment of inflammatory diseases. Immunol Rev 280(1):231-248. https://doi.org/10. 1111/imr.12572

12. Wattenberg MM, Fahim A, Ahmed MM, Hodge JW (2014) Unlocking the combination: potentiation of radiation-induced antitumor responses with immunotherapy. Radiat Res 182(2):126-138. https://doi.org/10.1667/rr13374.1

13. Wennerberg E, Lhuillier C, Vanpouille-Box C, Pilones KA, GarciaMartinez E, Rudqvist NP, Formenti SC, Demaria S (2017) Barriers to radiation-induced in situ tumor vaccination. Front Immunol 8:229. https://doi.org/10.3389/fimmu.2017.00229

14. Jelonek K, Pietrowska M, Widlak P (2017) Systemic effects of ionizing radiation at the proteome and metabolome levels in the blood of cancer patients treated with radiotherapy: the influence of inflammation and radiation toxicity. Int J Radiat Biol 93(7):683-696. https://doi.org/10.1080/09553002.2017.1304590

15. Siva S, MacManus M, Kron T, Best N, Smith J, Lobachevsky P, Ball D, Martin O (2014) A pattern of early radiation-induced inflammatory cytokine expression is associated with lung toxicity in patients with non-small cell lung cancer. PLoS One 9(10):e109560. https://doi.org/10.1371/journal.pone.0109560

16. Widlak P, Jelonek K, Wojakowska A, Pietrowska M, Polanska J, Marczak L, Miszczyk L, Skladowski K (2015) Serum proteome signature of radiation response: upregulation of inflammation-related factors and downregulation of apolipoproteins and coagulation factors in cancer patients treated with radiation therapy-a pilot study. Int J Radiat Oncol Biol Phys 92(5):1108-1115. https://doi.org/10. 1016/j.ijrobp.2015.03.040

17. Jelonek K, Pietrowska M, Ros M, Zagdanski A, Suchwalko A, Polanska J, Marczyk M, Rutkowski T, Skladowski K, Clench MR, Widlak P (2014) Radiation-induced changes in serum lipidome of head and neck cancer patients. Int J Mol Sci 15(4):6609-6624. https://doi.org/10.3390/ijms15046609

18. Matsumoto T, Kobayashi T, Kamata K (2007) Role of lysophosphatidylcholine (LPC) in atherosclerosis. Curr Med Chem 14(30): 3209-3220

19. Zhang W, Sun G, Aitken D, Likhodii S, Liu M, Martin G, Furey A, Randell E, Rahman P, Jones G, Zhai G (2016) Lysophosphatidylcholines to phosphatidylcholines ratio predicts advanced knee osteoarthritis. Rheumatology (Oxford) 55(9):1566-1574. https://doi. org/10.1093/rheumatology/kew207

20. Laiakis EC, Canadell MP, Grilj V, Harken AD, Garty GY, Astarita G, Brenner DJ, Smilenov L, Fornace AJ Jr. (2019) Serum lipidomic analysis from mixed neutron/X-ray radiation fields reveals a hyperlipidemic and pro-inflammatory phenotype. Sci Rep 9(1):4539. https://doi.org/10.1038/s41598-019-41083-7

21. Perkins JR, Dawes JM, McMahon SB, Bennett DLH, Orengo C, Kohl M (2012) ReadqPCR and NormqPCR: R packages for the reading, quality checking and normalisation of RT-qPCR quantification cycle (Cq) data. BMC Genomics 13:296-296. https://doi. org/10.1186/1471-2164-13-296

22. Donaubauer AJ, Ruhle PF, Becker I, Fietkau R, Gaipl US, Frey B (2019) One-tube multicolor flow cytometry assay (OTMA) for comprehensive immunophenotyping of peripheral blood. Methods Mol Biol 1904:189-212. https://doi.org/10.1007/978-1-49398958-4_8
23. Ruhle PF, Fietkau R, Gaipl US, Frey B (2016) Development of a modular assay for detailed immunophenotyping of peripheral human whole blood samples by multicolor flow cytometry. Int J Mol Sci 17(8):E1316. https://doi.org/10.3390/ijms17081316

24. de la Barca JMC, Huang NT, Jiao H, Tessier L, Gadras C, Simard G, Natoli R, Tcherkez G, Reynier P, Valter K (2017) Retinal metabolic events in preconditioning light stress as revealed by wide-spectrum targeted metabolomics. Metabolomics 13(3):22. https://doi.org/10. 1007/s11306-016-1156-9

25. Cohen J (1988) Statistical power analysis for the behavioral sciences, 2nd edn. Lawrence Earlbaum Associates, Hillsdale, NJ

26. Fritz CO, Morris PE, Richler JJ (2012) Effect size estimates: current use, calculations, and interpretation. J Exp Psychol Gen 141(1):2-18. https://doi.org/10.1037/a0024338

27. Wendt HW (1972) Dealing with a common problem in social science: a simplified rank-biserial coefficient of correlation based on the U statistic. Eur J Soc Psychol 2(4):463-465. https://doi.org/10. 1002/ejsp.2420020412

28. Kerby DS (2014) The simple difference formula: an approach to teaching nonparametric correlation. Comprehensive Psychology. https://doi.org/10.2466/11.it.3.1

29. Ihaka R, Gentleman R (1996) R: a language for data analysis and graphics. J Comput Graph Stat 5(3):299-314. https://doi.org/10. 1080/10618600.1996.10474713

30. Ricco A, Manahan G, Lanciano R, Hanlon A, Yang J, Arrigo S, Lamond J, Feng J, Mooreville M, Garber B, Brady L (2016) The comparison of stereotactic body radiation therapy and intensity-modulated radiation therapy for prostate cancer by NCCN risk groups. Front Oncol 6:184. https://doi.org/10.3389/fonc.2016.00184

31. Mercader M, Bodner BK, Moser MT, Kwon PS, Park ES, Manecke RG, Ellis TM, Wojcik EM, Yang D, Flanigan RC, Waters WB, Kast WM, Kwon ED (2001) T cell infiltration of the prostate induced by androgen withdrawal in patients with prostate cancer. Proc Natl Acad Sci U S A 98(25):14565-14570. https://doi. org/10.1073/pnas.251140998

32. Sutherland JS, Goldberg GL, Hammett MV, Uldrich AP, Berzins SP, Heng TS, Blazar BR, Millar JL, Malin MA, Chidgey AP, Boyd RL (2005) Activation of thymic regeneration in mice and humans following androgen blockade. J Immunol 175(4):2741-2753. https:// doi.org/10.4049/jimmunol.175.4.2741

33. Eckert F, Schaedle P, Zips D, Schmid-Horch B, Rammensee HG, Gani C, Gouttefangeas C (2018) Impact of curative radiotherapy on the immune status of patients with localized prostate cancer. OncoImmunology 7(11):e1496881. https://doi.org/10.1080/ 2162402X.2018.1496881

34. Hall J, Jeggo PA, West C, Gomolka M, Quintens R, Badie C, Laurent O, Aerts A, Anastasov N, Azimzadeh O, Azizova T, Baatout S, Baselet B, Benotmane MA, Blanchardon E, Gueguen Y, Haghdoost S, Harms-Ringhdahl M, Hess J, Kreuzer M, Laurier D, Macaeva E, Manning G, Pernot E, Ravanat JL, Sabatier L, Tack K, Tapio S, Zitzelsberger H, Cardis E (2017) Ionizing radiation biomarkers in epidemiological studies-an update. Mutat Res 771:59-84. https://doi.org/10.1016/j.mrrev.2017.01.001

35. van Meir H, Nout RA, Welters MJ, Loof NM, de Kam ML, van Ham JJ, Samuels S, Kenter GG, Cohen AF, Melief CJ, Burggraaf J, van Poelgeest MI, van der Burg SH (2017) Impact of (chemo)radiotherapy on immune cell composition and function in cervical cancer patients. OncoImmunology 6(2):e1267095. https://doi.org/10.1080/2162402X.2016.1267095

36. Schaue D, Comin-Anduix B, Ribas A, Zhang L, Goodglick L, Sayre JW, Debucquoy A, Haustermans K, McBride WH (2008) $\mathrm{T}$-cell responses to survivin in cancer patients undergoing radiation therapy. Clin Cancer Res 14(15):4883-4890. https://doi.org/10. 1158/1078-0432.CCR-07-4462

37. Krieg C, Nowicka M, Guglietta S, Schindler S, Hartmann FJ, Weber LM, Dummer R, Robinson MD, Levesque MP, Becher B 
(2018) High-dimensional single-cell analysis predicts response to anti-PD-1 immunotherapy. Nat Med 24(2):144-153. https://doi.org/ 10.1038/nm.4466

38. Belka C, Ottinger H, Kreuzfelder E, Weinmann M, Lindemann M, Lepple-Wienhues A, Budach W, Grosse-Wilde H, Bamberg M (1999) Impact of localized radiotherapy on blood immune cells counts and function in humans. Radiother Oncol 50(2):199-204

39. Sato H, Niimi A, Yasuhara T, Permata TBM, Hagiwara Y, Isono M, Nuryadi E, Sekine R, Oike T, Kakoti S, Yoshimoto Y, Held KD, Suzuki Y, Kono K, Miyagawa K, Nakano T, Shibata A (2017) DNA double-strand break repair pathway regulates PD-L1 expression in cancer cells. Nat Commun 8(1):1751. https://doi.org/10.1038/ s41467-017-01883-9

40. Falcke SE, Ruhle PF, Deloch L, Fietkau R, Frey B, Gaipl US (2018) Clinically relevant radiation exposure differentially impacts forms of cell death in human cells of the innate and adaptive immune system. Int J Mol Sci 19(11):E3574. https://doi.org/10.3390/ ijms19113574

41. Khaled YS, Elkord E, Ammori BJ (2012) Macrophage inhibitory cytokine-1: a review of its pleiotropic actions in cancer. Cancer Biomark 11(5):183-190. https://doi.org/10.3233/CBM-201200287

42. Emmerson PJ, Duffin KL, Chintharlapalli S, Wu X (2018) GDF15 and growth control. Front Physiol 9:1712. https://doi.org/10.3389/ fphys.2018.01712

43. Li S, Zhang QZ, Zhang DQ, Feng JB, Luo Q, Lu X, Wang XR, Li KP, Chen DQ, Mu XF, Gao L, Liu QJ (2017) GDF-15 gene expression alterations in human lymphoblastoid cells and peripheral blood lymphocytes following exposure to ionizing radiation. Mol Med Rep 15(6):3599-3606. https://doi.org/10.3892/mmr.2017. 6476

44. Sandor N, Schilling-Toth B, Kis E, Benedek A, Lumniczky K, Safrany G, Hegyesi H (2015) Growth differentiation factor-15 (GDF-15) is a potential marker of radiation response and radiation sensitivity. Mutat Res Genet Toxicol Environ Mutagen 793:142-149. https://doi.org/10.1016/j.mrgentox.2015.06.009

45. Bogdandi EN, Balogh A, Felgyinszki N, Szatmari T, Persa E, Hildebrandt G, Safrany G, Lumniczky K (2010) Effects of lowdose radiation on the immune system of mice after total-body irradiation. Radiat Res 174(4):480-489. https://doi.org/10.1667/ rr2160.1

46. Das M, Zhu C, Kuchroo VK (2017) Tim-3 and its role in regulating anti-tumor immunity. Immunol Rev 276(1):97-111. https://doi.org/ 10.1111/imr. 12520
47. Moller-Hackbarth K, Dewitz C, Schweigert O, Trad A, Garbers C, Rose-John S, Scheller J (2013) A disintegrin and metalloprotease (ADAM) 10 and ADAM17 are major sheddases of $\mathrm{T}$ cell immunoglobulin and mucin domain 3 (Tim-3). J Biol Chem 288(48):34529-34544. https://doi.org/10.1074/jbc.M113.488478

48. Zhang Y, Ma CJ, Wang JM, Ji XJ, Wu XY, Moorman JP, Yao ZQ (2012) Tim-3 regulates pro- and anti-inflammatory cytokine expression in human CD14+ monocytes. J Leukoc Biol 91(2):189-196. https://doi.org/10.1189/jlb.1010591

49. Candeias SM, Testard I (2015) The many interactions between the innate immune system and the response to radiation. Cancer Lett 368(2):173-178. https://doi.org/10.1016/j.canlet.2015.02.007

50. Rothammer A, Sage EK, Werner C, Combs SE, Multhoff G (2019) Increased heat shock protein 70 (Hsp70) serum levels and low NK cell counts after radiotherapy-potential markers for predicting breast cancer recurrence? Radiat Oncol 14(1):78. https://doi.org/ 10.1186/s13014-019-1286-0

51. Siva S, Lobachevsky P, MacManus MP, Kron T, Moller A, Lobb RJ, Ventura J, Best N, Smith J, Ball D, Martin OA (2016) Radiotherapy for non-small cell lung cancer induces DNA damage response in both irradiated and out-of-field normal tissues. Clin Cancer Res 22(19):4817-4826. https://doi.org/10.1158/1078-0432.CCR-160138

52. Lobachevsky PN, Ventura J, Giannakandropoulou L, Forrester H, Palazzolo JS, Haynes NM, Stevenson AW, Hall CJ, Mason J, Pollakis G, Pateras IS, Gorgoulis V, Terzoudi GI, Hamilton JA, Sprung CN, Georgakilas AG, Martin OA (2019) A functional immune system is required for the systemic genotoxic effects of localized irradiation. Int J Radiat Oncol Biol Phys 103(5):1184-1193. https://doi.org/10.1016/j.ijrobp.2018.11.066

53. Ventura J, Lobachevsky PN, Palazzolo JS, Forrester H, Haynes NM, Ivashkevich A, Stevenson AW, Hall CJ, Ntargaras A, Kotsaris V, Pollakis GC, Potsi G, Skordylis K, Terzoudi G, Pateras IS, Gorgoulis VG, Georgakilas AG, Sprung CN, Martin OA (2017) Localized synchrotron irradiation of mouse skin induces persistent systemic genotoxic and immune responses. Cancer Res 77(22):6389-6399. https://doi.org/10.1158/0008-5472.CAN-171066

54. Sage EK, Schmid TE, Geinitz H, Gehrmann M, Sedelmayr M, Duma MN, Combs SE, Multhoff G (2017) Effects of definitive and salvage radiotherapy on the distribution of lymphocyte subpopulations in prostate cancer patients. Strahlenther Onkol 193(8):648-655. https://doi.org/10.1007/s00066-017-1144-7 